\title{
Neanderthales y humanos modernos: perspectivas a partir de la dinámica ecológica
}

Clive Finlayson, profesor del Departamento de Antropología de la Universidad de Toronto y Director del Museo de Gibraltar, fue el encargado de dirigir las XXIV Jornadas Arqueológicas del Museo Arqueológico Municipal de El Puerto de Santa María (Cádiz), durante los días 21, 22 y 23 de julio de 2004, bajo el título genérico "Neanderthales y Humanos Modernos. Nuevas perspectivas a partir de la dinámica ecológica".

Desde que, hace 24 años, se pusieron en marcha las Jornadas Arqueológicas, por el Museo Arqueológico de El Puerto han pasado los más prestigiosos arqueólogos, prehistoriadores, paleontólogos y paleocólogos, impartiendo y transmitiendo las investigaciones y conocimientos más avanzados en cada una de las especialidades. Con la organización de estos "forum" a modo de jornadas especializadas, el Museo pretende la divulgación científica en líneas de investigación poco comunes en el contexto de la arqueología en general. En la actualidad, los cursos se han convertido en una referencia de primer orden entre las convocatorias de cursos de verano en el ámbito nacional.

En esta última edición, las jornadas intentaron tratar un tema que en la actualidad es "punta de lanza" en las investigaciones prehistóricas y paleontropológicas en todos los centros de debate e investigación: los diversos aspectos comparativos y problemática del poblamiento de los Humanos Modernos y Neanderthales, los ciclos glaciares y su repercusión en el Continente Africano, medios ecológicos comparativos y extinción de las poblaciones de Neanderthales y poblamiento del grupo de Humanos Modernos.

Los temas abordados, y coordinados por Francisco Giles Pacheco (director del Museo Arqueológico Municipal), fueron:

$>$ Evolución Humana en el Pleistoceno

$>$ Dinámica biogeográfica

$>$ La dinámica de colonización y extinción; ejemplo de Europa

> Comparación del Medio Ambiente y ecología de los Neanderthales y Humanos Modernos

> Las condiciones en África y Eurasia durante el último Ciclo Glaciar

> "Colonización" de los Humanos Modernos y la extinción de los Neanderthales

> Valoración global y referencias

La exposición de los resultados más recientes indican con claridad la permanencia tardía de los neanderthales o de las industrias musterienses en el Sur de la Península Ibérica, quizás aún más próximos que los $30 \mathrm{ka}$. Estos datos han Ilevado a ciertos autores a replantear la hipótesis de que existió a finales del Paleolítico Medio una "frontera del Ebro". Según estos autores, el valle del Ebro formaría una barrera por un periodo dilatado de entre 5 y 10 mil años que permitió la existencia alopátrida de neanderthales (al sur) y humanos anatómicamente modernos (al norte).

En nuestra opinión, esta interpretación no es totalmente correcta y necesita una reevaluación teniendo en cuenta los factores bioclimáticos de la Península Ibérica. En consecuencia los neanderthales no eran por tanto especie adaptada a los fríos glaciares y desarrollaban preferentemente sus actividades en las "sabanas" y los humedales mediterráneos donde abundaban los recursos naturales.

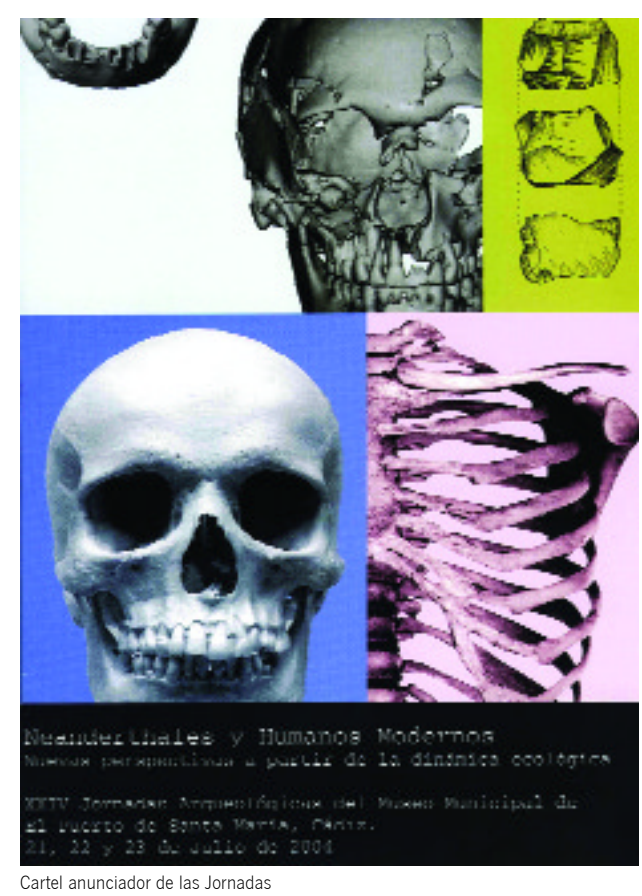

Queda claro que el Sur de la Península Ibérica, en particular las zonas mediterráneas y las de contacto con las cuencas del Guadalete y Guadalquivir tienen un gran significado dentro del estudio de la últimas poblaciones de neanderthales Ibéricos, constatándose la ocupación humana durante el Paleolítico Medio en Andalucia, demostrándose cómo estas poblaciones desarrollaban sus actividades en torno a ciclos (con toda probabilidad estacionales) que incorporaban zonas costeras, lacustres o riverinas y también zonas serranas con enclaves estratégicos en pasos de montaña.

Francisco Giles Pacheco

Coordinador de las Jornadas 